\title{
Electronic cigarette vapour enhances pneumococcal adherence to airway epithelial cells under abnormal conditions of exposure
}

\author{
To the Editor:
}

We read with great interest the research article by MiYashita et al. [1], in which the authors showed that e-cigarette aerosol emissions increase platelet-activating factor receptor (PAFR) expression and, consequently, Streptococcus pneumoniae adhesion to human airway epithelial cells. These findings led authors to conclude that e-cigarette use has the potential to increase susceptibility to pneumococcal infection. Unfortunately, the evidence presented in the paper is inadequate to provide much confidence in this conclusion.

Although the parameters for the generation of e-cigarette aerosol emissions for the in vitro exposure studies have not been specified, we estimated a very short inter-puff period $(<10 \mathrm{~s})$ for a round of 25 consecutive puffs during the 5-min procedure. Under such extreme experimental conditions, high-powered e-cigarettes are known to generate high levels of toxicants [2]. That this is the case is also confirmed by the high levels of metals in the e-cigarette vapour extract reported by the authors themselves (see table S1 of that article). Therefore, it is not surprising that under abnormal conditions of use, e-cigarette vapour has the capacity to induce oxidative stress. We conclude that the in vitro experimental conditions of the study are unlikely to reflect normal conditions of airway exposure. The use of standardised regime [3] to generate e-cigarette aerosol emissions is recommended for more realistic in vitro experiments.

An additional challenge in interpreting the results is the highly variable level of adhesiveness of S. pneumoniae strain D39 to human airway epithelial cells (A549). Differences of several orders of magnitude have been reported by the same researchers and by others under similar experimental conditions [1, 4-7]. Consequently, even though statistically significant, findings by MrYASHITA et al. [1] cast more doubts than certainties about their effective microbiological predictivity.

The observed small increase in nasal epithelial PAFR expression shown after 5 min of vaping is essentially an indication of a nonspecific, transient cellular response, and is of no clinical relevance or prognostic significance. That this is the case is also confirmed by the authors' own data. Nasal epithelial PAFR expression at baseline was no different between exclusive regular vapers and healthy never-smokers controls.

Last but not least, given that persistent airway exposure to cigarette smoke is known to promote infection susceptibility, it is not surprising that abstaining from tobacco smoking by switching to e-cigarettes may explain an attenuation in respiratory infections [8]. Evidence from real-life surveys [9] and clinical studies of respiratory patients $[10,11]$ supporting a marked decrease in respiratory infections with regular e-cigarette use is in stark contrast with the concerns raised by MiYASHITA et al. [1] that e-cigarette use has the potential to increase susceptibility to pneumococcal infection. Moreover, despite millions of regular e-cigarette users worldwide, there has been no evidence of new emerging pneumonia outbreaks in recent years or reports of infectious pneumonia in the medical literature.

@ERSpublications

E-cigarette vapour enhances pneumococcal adherence to airway epithelial cells under "abnormal" conditions of exposure http://ow.ly/O9J030keaYe

Cite this article as: Caruso $\mathrm{M}$, Emma $\mathrm{R}$, Fuochi V, et al. Electronic cigarette vapour enhances pneumococcal adherence to airway epithelial cells under abnormal conditions of exposure. Eur Respir J 2018; 52: 1800915 [https://doi.org/10.1183/13993003.00915-2018]. 
Massimo Caruso $\odot^{1}$, Rosalia Emma ${ }^{1}$, Virginia Fuochi ${ }^{2}$, Pio M. Furneri ${ }^{2,3}$ and Riccardo Polosa ${ }^{1,3}$

${ }^{1}$ Dept of Clinical and Experimental Medicine (MEDCLIN), University of Catania, Catania, Italy. ${ }^{2}$ Dept of Biomedical and Biotechnological Sciences, University of Catania, Catania, Italy. ${ }^{3}$ Center of Excellence for the Acceleration of Harm Reduction (CoEHAR), University of Catania, Catania, Italy.

Correspondence: Massimo Caruso, MEDCLIN, University of Catania, Via S. Sofia 78, 95123 Catania (CT), Italy. E-mail: mascaru@unict.it

Received: May 162018 | Accepted: May 162018

Published online September 6, 2018; republished October 10, 2018 with amendments to the conflict of interest disclosure statement.

Conflict of interest: R. Polosa reports personal fees for consultancy from ECITA (Electronic Cigarette Industry Trade Association), UK, grants and personal fees from Pfizer, and personal fees from Health Diplomat (a consulting company that delivers solutions to global health problems with special emphasis on harm minimisation); R. Polosa also reports nonfinancial support (advisory board work and communication support) for Lega Italiana Anti Fumo, and has acted as a convenor for CEN/TC 437; WG4, outside the submitted work. Previously R. Polosa has received lecture fees and research funding from Pfizer and GlaxoSmithKline, manufacturers of stop-smoking medications; and also served as a consultant for Global Health Alliance for treatment of tobacco dependence. Lecture fees from a number of European electronic cigarette industry and trade associations (including FIVAPE in France and FIESEL in Italy) were directly donated to vaper advocacy non-profit organisations. Support in the area of tobacco control has also been received from The Consumer Advocates for Smoke-free Alternatives, Arbi Group Srl (the Italian distributor for Categoria electronic cigarettes), CV Therapeutics, NeuroSearch A/S, Sandoz, MSD, Boehringer Ingelheim, Novartis, Duska Therapeutics and Forest Laboratories. Publication costs for previous work have been met by Happy Liquid, Ritchy Europe, Cuts Ice e-Liquid Laboratories and VDLV e-Liquids.

\section{References}

1 Miyashita L, Suri R, Dearing E, et al. E-cigarette vapour enhances pneumococcal adherence to airway epithelial cells. Eur Respir J 2018; 51: 1701592.

2 Farsalinos KE, Polosa R. Safety evaluation and risk assessment of electronic cigarettes as tobacco cigarette substitutes: a systematic review. Ther Adv drug Saf 2014; 5: 67-86.

3 CORESTA E-Cigarette Task Force. Routine Analytical Machine for E-Cigarette Aerosol Generation and Collection - Definitions and Standard Conditions. Paris, CORESTA, 2015.

4 Mushtaq N, Ezzati M, Hall L, et al. Adhesion of Streptococcus pneumoniae to human airway epithelial cells exposed to urban particulate matter. J Allergy Clin Immunol 2011; 127: 1236-1242.

5 Hammerschmidt S, Wolff S, Hocke A, et al. Illustration of pneumococcal polysaccharide capsule during adherence and invasion of epithelial cells. Infect Immun 2005; 73: 4653-4667.

6 Grigg J, Miyashita L, Suri R. Pneumococcal infection of respiratory cells exposed to welding fumes; role of oxidative stress and HIF-1 alpha. PLoS One 2017; 12: e0173569.

7 Nguyen CT, Le N-T, Tran TD-H, et al. Streptococcus pneumoniae ClpL modulates adherence to A549 human lung cells through Rap1/Rac1 activation. Infect Immun 2014; 82: 3802-3810.

8 Campagna D, Amaradio MD, Sands MF, et al. Respiratory infections and pneumonia: potential benefits of switching from smoking to vaping. Pneumonia (Nathan Qld) 2016; 8: 4.

9 Farsalinos KE, Romagna G, Tsiapras D, et al. Characteristics, perceived side effects and benefits of electronic cigarette use: a worldwide survey of more than 19,000 consumers. Int J Environ Res Public Health 2014; 11: 4356-4373.

10 Polosa R, Morjaria JB, Caponnetto P, et al. Evidence for harm reduction in COPD smokers who switch to electronic cigarettes. Respir Res 2016; 17: 166.

11 Polosa R, Morjaria JB, Caponnetto P, et al. Persisting long term benefits of smoking abstinence and reduction in asthmatic smokers who have switched to electronic cigarettes. Discov Med 2016; 21: 99-108.

Copyright @ERS 2018

From the authors:

M. Caruso and co-workers raise several points related to our electronic cigarette (EC) study [1]. First, they suggest that we generated EC vapour (ECV) under "extreme" experimental conditions, which could lead to overheating and thermal decomposition of E-liquids around a heated coil [2]. However, we minimised the potential effect of coil overheating by ensuring that the EC reservoir was always more than three quarters full, and by using a low power second generation EC device $(3.7 \mathrm{~V})$, instead of a later generation $8 \mathrm{~V}$ device, which would have an increased potential for substantially higher coil temperatures and under-dry

@ERSpublications

Studies using cultures of human airway cells provide important insights into the toxicity of vaping http://ow.ly/Pj7X30kM9h3

Cite this article as: Grigg J. Response to: Electronic cigarette vapour enhances pneumococcal adherence to airway epithelial cells under abnormal conditions of exposure. Eur Respir J 2018; 52: 1801199 [https://doi. org/10.1183/13993003.01199-2018]. 


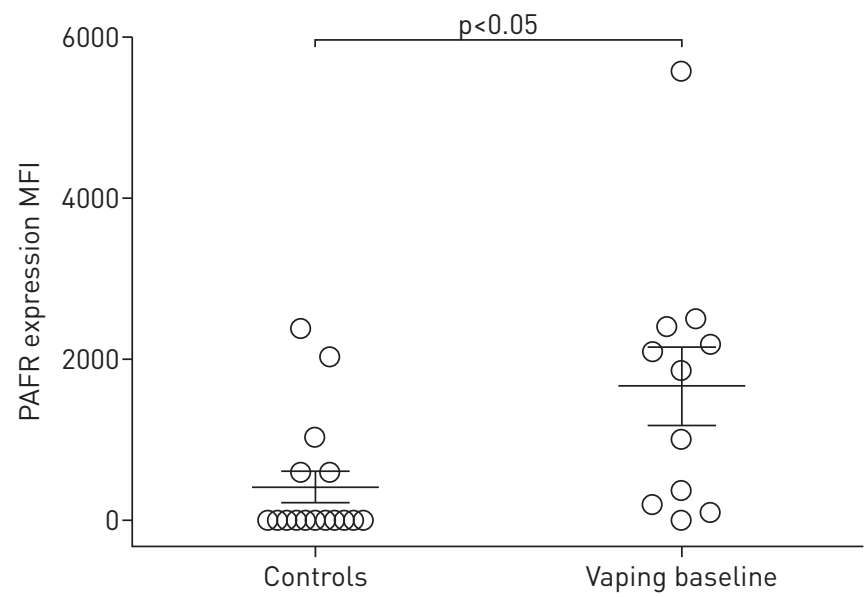

FIGURE 1 Platelet-activating factor receptor (PAFR) expression in nasal epithelial cells from vaping adults prior to experimental electronic cigarette vapour exposure (baseline) and in non-vaping controls. Non-vaping healthy controls are those recruited for vaping study [1], supplemented by controls recruited for a previous welding fume exposure study $(n=10)[6]$. Bar represents mean (with standard error of the mean shown) and data are analysed by unpaired t-test.

conditions [2]. In addition, our use of a 4-s puff duration and 8-s interpuff interval cannot be regarded as extreme, since a recent long-term study of young vaping adults found that one inhalation pattern is multiple rapid puffs taken over very short time periods [3]. Furthermore, the production of toxins under extreme conditions in vitro does not explain why we found that a "normal" vaping session increased nasal platelet-activating factor receptor (PAFR) expression in adult volunteers.

The authors' second point is related to differences in pneumococcal adhesion compared with previous reports. Since exposure dose and duration was optimised in these in vitro studies, data are not directly comparable. For example, in our previous studies, airway cells were exposed in vitro to particulate matter [4] and welding fumes [5] for $4 \mathrm{~h}$ and $2 \mathrm{~h}$ respectively, compared to $2.5 \mathrm{~h}$ for exposure to ECV [1]. Since welding fume particles and fossil fuel-derived particulate matter adhere firmly to cells in vitro, we also needed an increased number of washes to remove particles before adding pneumococci. Caruso and co-workers also quote an adhesion study done by a separate group, but this group used $1 \times 10^{5}$ airway cells per well, compared to our initial seeding of $2 \times 10^{5}$ cells per well with overnight incubation to allow confluency. These experimental differences, not unsurprisingly, result in quantitative differences in pneumococcal adhesion. But the relative changes in pneumococcal adhesion between studies are broadly similar. For example, there was a median 3.1-fold increase in pneumococcal adhesion to A549 cells exposed to mild steel welding fume particles [5], compared to a 2.6- and 2.9-fold increased for nicotine-free ECV and nicotine containing ECV-exposed cells, respectively [1].

Third, M. Caruso and co-workers claim that the increase in PAFR at $5 \mathrm{~min}$ after a vaping session, and the lack of difference between nasal PAFR expression prior to vaping compared with healthy controls, means that our data are of "zero clinical significance". As clearly stated throughout the paper, we measured nasal PAFR expression at $1 \mathrm{~h}$ post vaping, thus the (median) 6-fold increase in PAFR does not reflect either a transient or an irrelevant response. Since vapers had not inhaled ECV for $24 \mathrm{~h}$ before the study, and pre-vape nasal PAFR expression was not significantly different from healthy volunteers, our data are, on one hand, compatible with downregulation of nasal PAFR by $24 \mathrm{~h}$. On the other hand, it is also possible that our study was underpowered for this secondary outcome. Indeed, combining nasal PAFR expression data from the healthy volunteers from the ECV study with PAFR expression data from 10 volunteers reported in our previous study of welding fumes, analysed using the same methodology [6], suggests that nasal PAFR expression in vapers is persistently increased (figure 1).

Overall our data are compatible with the recent position statement of the Forum of International Respiratory Societies that "exposure to EC aerosol in adolescence and early adulthood is not risk-free and can result in pulmonary toxicity" [7], and the recent consensus study report of the National Academies of Sciences, Engineering and Medicine, that concluded that "studies to date provide moderate evidence supporting short-term adverse effects of nicotine-containing e-cigarettes on lung defence mechanisms" [8]. Unfortunately, the studies quoted by Caruso and co-workers to support their statement that regular vaping "markedly decreases" respiratory infections (presumably compared with cigarette smoking) are not relevant to the important question of adverse health effects on young, non-smoking, people encouraged to use ECs by their attractive flavours and advertising. We therefore consider that mechanistic studies using 
airway cell cultures and experimental exposure of both animals and humans are critical to signposting potential toxicities, including vulnerability to bacterial airway infection. To dismiss mechanistic studies, as done for example by the authors of a 2015 report published by Public Health England [9], who concluded that the study of SusSAN et al. [10] that reported defective clearance of S. pneumoniae from the lungs of mice exposed to ECV for 2 weeks "has little relevance for estimating human risk and it does not raise any new safety concerns", is not in the spirit of the precautionary approach required when assessing environmental threats to children and young people.

\section{Jonathan Grigg}

Centre for Paediatrics, Queen Mary University London, London, UK.

Correspondence: Jonathan Grigg, Queen Mary University London, Centre for Paediatrics, Blizard Institute, 4 Newark Street, London E12AT, UK. E-mail: j.grigg@qmul.ac.uk

Received: June 272018 | Accepted: June 272018

Conflict of interest: J. Grigg reports honoraria for advisory board work from GSK and Vifor Pharmaceuticals, and honoraria for lectures from Novartis, outside the submitted work.

\section{References}

1 Miyashita L, Suri R, Dearing E, et al. E-cigarette vapour enhances pneumococcal adherence to airway epithelial cells. Eur Respir J 2018; 51: 1701592.

2 Chen $\mathrm{W}$, Wang $\mathrm{P}$, Ito $\mathrm{K}$, et al. Measurement of heating coil temperature for e-cigarettes with a 'top-coil' clearomizer. PLoS One 2018; 13: e0195925.

3 Robinson RJ, Hensel EC, Roundtree KA, et al. Week long topography study of young adults using electronic cigarettes in their natural environment. PLoS One 2016; 11: e0164038.

4 Mushtaq N, Ezzati M, Hall L, et al. Adhesion of Streptococcus pneumoniae to human airway epithelial cells exposed to urban particulate matter. J Allergy Clin Immunol 2011; 127: 1236-1242.

5 Suri R, Periselneris J, Lanone S, et al. Exposure to welding fumes and lower airway infection with Streptococcus pneumoniae. J Allergy Clin Immunol 2016; 137: 527-534.

6 Grigg J, Miyashita L, Suri R. Pneumococcal infection of respiratory cells exposed to welding fumes: role of oxidative stress and HIF-1 alpha. PLoS One 2017; 12: e0173569.

7 Ferkol TW, Farber HJ, La Grutta S, et al. Electronic cigarette use in youths: a position statement of the Forum of International Respiratory Societies. Eur Respir J 2018; 51: 1800278.

8 Eaton DL, Kwan LY, Stratton K, eds. National Academies of Sciences, Engineering, and Medicine.Public Health Consequences of E-Cigarettes. Washington, The National Academies Press, 2018. Available from: www.nap.edu/ catalog/24952/public-health-consequences-of-e-cigarettes

9 McNeill A, Brose LS, Calder R, et al. E-cigarettes: an Evidence Update. A Report Commissioned by Public Health England. London, Public Health England, 2015. Available from: https://assets.publishing.service.gov.uk/ government/uploads/system/uploads/attachment_data/file/457102/Ecigarettes_an_evidence_update_A_report_ commissioned_by_Public_Health_England_FINAL.pdf

10 Sussan TE, Gajghate S, Thimmulappa RK, et al. Exposure to electronic cigarettes impairs pulmonary anti-bacterial and anti-viral defenses in a mouse model. PLoS One 2015; 10: e0116861. 